\title{
A Case of Diffuse Cutaneous Leishmaniasis in a HIV Positive Patient
}

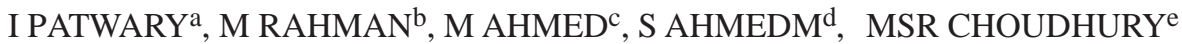

\section{Summary:}

A cultivator of 30 years of age presented with fever, cough, diarrhoea, anorexia and weight loss for 6 months and papulonodular skin lesions for one month. Skin lesions appeared on the face, first over the left cheek and gradually involved whole of his face, extremities and external genitalia sparing the trunk. Skin biopsy from the nodule

\section{Introduction:}

Leishmania/human immunodeficiency virus (HIV) coinfection is emerging as an increasingly frequent and extremely serious new disease. Although many reports have described the association of visceral leishmaniasis and HIV, cutaneous leishmaniasis is associated with HIV is very uncommon ${ }^{1,2}$. Diffuse cutaneous leishmaniasis may be a common clinical manifestation when leishmaniasis associated with HIV infection ${ }^{3}$. Leishmaniasis covers three well-individualized clinical variants, each due to individual species found in different geographic areas, viz, visceral, cutaneous and mucocutaneous. It is transmitted by female Phlebotomus sandflies. Human immunodeficiency virus (HIV) infection is increasing worldwide and several reports indicate a rising trend of VL / HIV co-infection, modifying the traditional anthroponotic pattern of VL transmission ${ }^{4}$. Observed clinical forms of cutaneous

a. Dr. Ismail Patwary, Professor of Medicine, Sylhet M.A.G. Osmani Medical College

b. Dr. Matiur Rahman, Associate Professor of Neurology, Sylhet M.A.G. Osmani Medical College, Sylhet

c. Dr. Moniruzzaman Ahmed, Assistant Prof. of Medicine, Sylhet M.A.G. Osmani Medical College.

d. Dr. Saleh Ahmed, Registrar of Medicine, Sylhet M.A.G. Osmani Medical College, Sylhet.

e. Dr. Mohammad Saidur Rahman Choudhury, Fellowship Trainee, department of medicine. Sylhet M.A.G. Osmani Medical College, Sylhet.

Address of Correspondence: Dr. Matiur Rahman, Associate Professor of Neurology, Sylhet M.A.G. Osmani Medical College, Sylhet, Bangladesh, E-mail: ma5ti@yahoo.com

Received : 24 October, 2009

Accepted : 31 January 2011 showed collection of histiocytes, lymphocytes \& plasma cells with plenty of LD bodies inside the histiocytes. Screening test for HIV was positive and it was confirmed with western blot. Probably this is the first case Leishmaniasis/ HIV co infection reported from Bangladesh.

(J Bangladesh Coll Phys Surg 2011; 29: 106-108)

leishmaniasis are: papulo-nodular, ulcerative, infiltrative, lepromatous and diffuse, psoriasis-like, cheloid, histioid or kaposi-like. Some patients presented with more than one clinical form ${ }^{5}$. L. major is responsible for typical cutaneous leishmaniasis but particular clinical forms have been described in immunodeficient patients, especially with diffuse cutaneous involvement. Here we reported a patient with diffuse cutaneous leishmaniasis with AIDS from Bangladesh.

\section{Case Report:}

A cultivator of 30 years of age, from Sylhet, Bangladesh was admitted in department of medicine, Sylhet MAG Osmani Medical College Hospital on $26^{\text {th }}$ April'09 with the complaints of fever, cough, diarrhoea, anorexia and weight loss for 6 months and papulonodular skin lesions for one month.

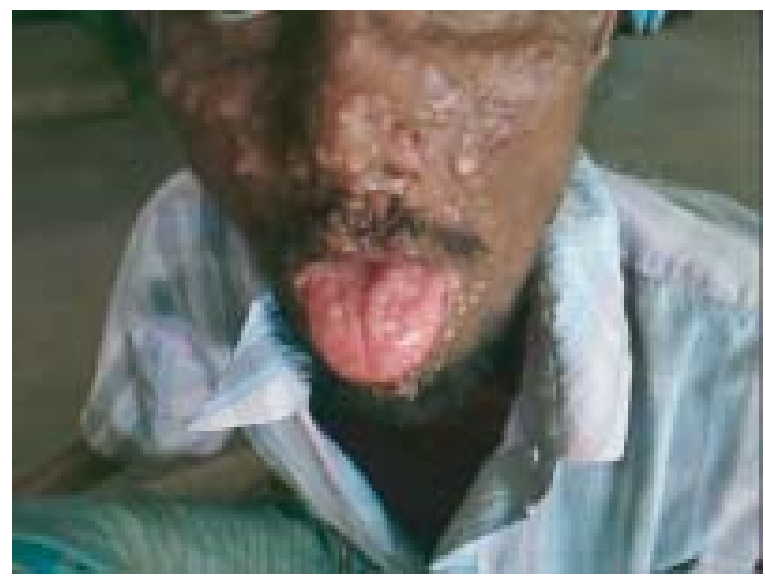

Fig.-1: Papulonodular lesions concentrated in central part of face 


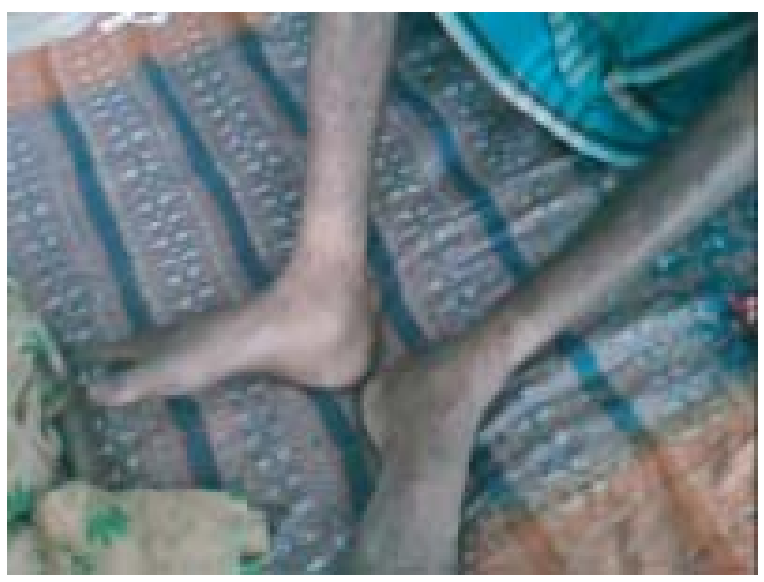

Fig.-2: Skin lesions also involving extremities

He stated that his fever was low grade, continuous and associated with cough with mucopurulent sputum and occasional haemoptysis. He also complained of frequent loose stools. He had significant weight loss over last six months. For the last one month he had noticed multiple papulo-nodular skin lesions appearing on the face, first over the left cheek and gradually involved whole of his face, extremities and external genitalia sparing the trunk.

Examination revealed he was grossly emaciated, body temperature of $101^{\circ} \mathrm{F}$, pulse rate $88 / \mathrm{min}$, respiratory rate 20 breaths/min, and a blood pressure of 90/50 $\mathrm{mm}$ of Hg. He was severely anaemic with mild oedema. Multiple light brown papulo-nodular skin lesions involving the face and both upper and lower extremities were noted. The nodules were more concentrated in central part of face and there was involvement of ears also (figure-1). Few of the nodules near the nose were crusted. The extremities were mainly involved by papules than nodules (figure-2). Trunk was relatively free .There were multiple hypo \& hyper pigmented patches over the abdomen. Sensations were intact over these areas. Examination of oral cavity revealed multiple erosions in the inner cheek and tongue and a whitish coating extending from dorsum of tongue up to oropharynx. There was no organomegaly. Complete blood count (CBC) showed a raised ESR $60 \mathrm{~mm} / \mathrm{1}^{\mathrm{st}}$ hour; a hemoglobin of $6.5 \mathrm{~g} / \mathrm{dl}$, with white cell count 5000/cmm, differential count N-50\% \& L-45\% and a platelet count $160,000 / \mathrm{cmm}$. The peripheral blood picture, RBS, renal function \& tuberculin test were unremarkable. The chest X-ray, ECG, USG of whole abdomen did not show any abnormalities. Sputum for AFB \& slit skin smear for leprosy were also negative.

Skin biopsy from the nodule showed collection of histiocytes, lymphocytes \& plasma cells with plenty of LD bodies inside the histiocytes. Screening test for HIV is positive and it was confirmed with western blot.

\section{Discussion:}

Leishmaniasis/human immunodeficiency virus (HIV) coinfection is emerging as an increasingly frequent and extremely serious new disease although it is very uncommon ${ }^{1,3}$. Human immunodeficiency virus (HIV) infection is increasing worldwide and several reports indicate a rising trend of VL / HIV co-infection, modifying the traditional anthroponotic pattern of VL transmission. ${ }^{4}$ Here we reported a patient with diffuse cutaneous leishmaniasis with HIV from Sylhet, Bangladesh. Barro-Traoré F et al reported A 38-years old HIV-positive man presenting with generalized, copper-coloured, painless, infiltrated, itching, papulonodular lesions present over the previous 10 months. ${ }^{6}$ The case we reported here also presented with multiple light brown papulo-nodular skin lesions involving the face and both upper and lower extremities. Some patients may present with more than one clinical form. ${ }^{6}$ This patient also presented with more than one lesion.

Although India is one of the countries having the largest burden of Leishmaniasis; nevertheless, there are very few HIV \& leishmania co-infection cases reported till date. ${ }^{4}$ Same comment is true for Bangladesh. Probably this is the first case of leishmaniasis \& HIV co infection reported from Bangladesh. Most of the HIV infected persons in Bangladesh were ex- workers in other countries specially middle east. This is the first case that never travelled outside the country.

\section{Conclusion:}

HIV is spreading alarmingly in Bangladesh especially in Sylhet. Most of them are ex workers in Middle eastern countries. This patient never travelled outside. This means he acquired infection inside country and indicates HIV is spreading in between our population. HIV \& leishmaniasis co-infection is a very rare occurrence and it modifies the presentation of leishmaniasis. Physicians should remain cautious and vigilant regarding this coinfection where HIV infection is common. 


\section{References:}

1. Pourahmad M, Hooshmand F, Rahiminejad M. Int J Dermatol. Cutaneous Leishmaniasis associated with visceral Leishmaniasis in a case of acquired immunodeficiency syndrome (AIDS). Int J Dermatol 2009 Jan;48(1):59-61

2. Roselino AM, Chociay MF, Costa RS, Machado AA, Figueiredo JF. L. (L.) chagasi in AIDS and visceral Leishmaniasis (kala-azar) co-infection. Rev Inst Med Trop Sa Paulo 2008 Jul-Aug; 50(4):251-4.

3. Pérez C, Solías Y, Rodríguez G.Biomedica. Diffuse cutaneous leishmaniasis in a patient with AIDS. Biomedica 2007 Mar; 27(1):149.

4. Kumar P, Sharma PK, Jain RK, Gautam RK, Bhardwaj M, Kar HK. Oral ulcer as an unusual feature of visceral leishmaniasis in an AIDS patient. Indian J Med Sci 2007 Feb;61(2):97-101.

5. Niamba P, Traoré A, Goumbri-Lompo O, Labrèze C, TraoréBarro F, Bonkoungou M, Ilboudo L, Gaulier A, Soudré BR. Cutaneous leishmania in HIV patient in Ouagadougou: clinical and therapeutic aspects. Ann Dermato Venereol 2006 Jun-Jul; 133(6-7):537-42.

6. Barro-Traoré F, Preney L, Traoré A, Darie H, Tapsoba P, Bassolé A, Sawadogo S, Niamba P, Grosshans E, Geniaux M. Cutaneous Leishmaniasis due to Leishmania major involving the bone marrow in an AIDS patient in Burkina Faso. Ann Dermato Venereol 2008 May; 135(5):380-3. Epub 2008 Apr 18. 